\title{
Impact of Financial Development on Economic Growth in Iran
}

\author{
Shahrouz Keshavarzi ${ }^{1}$ \\ Master student of Economics, University of Ataturk, Turkey \\ Prof. Dr Yusuf Akan \\ Department of Economics, Atatürk University, Erzurum
}

DOI: $\quad 10.6007 /$ IJARBSS/v4-i4/777 URL: http://dx.doi.org/10.6007/IJARBSS/v4-i4/777

\section{Abstract}

Always, financial sector has a central role in development and economic growth. Hence the relationship between financial development and economic growth appears to be essential. This article examines the impact of financial development on economic growth, with consider other variables affecting the economic growth, such as ratio of commercial, domestic investment and interest rate.

The time period used in this study is related to the years 1980 to 2013. It also explains their method of distribution breaks (ARDL) is used to assess relationships between variables.

This study estimates a relationship between variables within a Auto regressive Distributed Lag framework over the periods. The results of this study represents a significant and positive impact of financial development on economic growth. Also domestic investment has a positive and significant impact on economic growth, and Interest rate has a significant negative impact on economic growth.

Key words: Financial development, Economic growth, Autoregressive Distributed Lag Model, Economy of Iran.

\section{Introduction}

The financial sector plays a central role in economic growth and development and to play a mediating role in allocation of resources to all economic sectors, and to encourage the reduction of financing costs, efficient use of the savings, major contribution to the long-term economic growth.

The possible arrival of oil revenues in oil-exporting countries relying extensively on financial markets and changes in it. The main objective of such policy changes, stimulating economic growth. However, studies in this field show that financial development does not necessarily lead to economic growth. Patrick believes that the relationship between financial development and economic growth depends on the degree of development of each country. In the early stages of development, financial services and develop new

1.E-mail :Keshavarz.shahrouz@gmail.com (Corresponding) 
tools to improve the economic and financial structure of economic growth. However, continuing economic development, the demand for the following financial developments and demand for new types of financial instruments and services is the determining factor. (Patrick, 1966) In recent decades, the role of financial development in economic growth has been forgotten that a major issue is the lack of data needed in this area. The impact of the financial sector on economic growth over the study Goldsmith dates in his study emphasizes the growth and development of the financial system . (Goldsmith, 1969).

\section{2 . Theoretical background and research}

\section{2-1. Foreign Studies}

Influence financial development on economic growth is one of the main issues raised in the literature is that economic growth has accounted for much debate.

In a study titled " Financial sector development and sustainable economic growth in the markets for regional integration ", to explore the development of financial markets (banking sector) and economic growth in seven countries in the Middle East and North Africa in the period 1965 to 2002 pay. He concluded that six of the seven countries the banking sector to increase economic growth .vector error correction model, both in the short -term development of the banking sector has a significant impact on economic growth in these countries (Ritab, 2007).

Solomon and Head, in his study entitled "Financial Development and Economic Growth Experience Egypt", to investigate and analyze the relationship between financial development and economic growth in Egypt during the period from 1960 to 2001 began. The results suggest a relationship between financial development and economic growth in Egypt, they also proved that financial development through increased investment in resources for investment and

increase the efficiency of the country's economic growth. They proposed that the reform of the financial structure of the country in 1991 started to accelerate, stimulate investment and savings, and thus causes long-term economic growth (Suleiman and Aamer, 2007).

Ben Naceur and Ghazouani, study entitled " The stock market, banks, and economic growth : empirical evidence from the Middle East and North Africa ", using an unbalanced panel data models to examine the relationship between financial development and economic growth in eleven countries Middle East and North Africa . Lack of communication, the underdevelopment of markets and financial systems in the region which has hampered economic growth. Therefore, to improve economic growth in the region, system performance, and financial institutions should be improved . Based on the results of this study, other regions such as Africa, Eastern Europe or Latin America that have similar financial situation should improve their financial performance, stock market volatility has a negative impact on economic growth will be reduced (Ben Naceur and Ghazouani, 2007).

James, in a study titled " Financial Development and Economic Growth in Malaysia, what is the mechanism ? " To examine the effect of financial development on economic growth in Malaysia has a variety of channels. His study of this mechanism in their study of six 
equations are estimated. Results of estimating equations showed that financial development by increasing savings and private investment, stimulated economic growth in Malaysia is high. The results of his studies, the induction hypothesis that financial development and growth, and that the financial development of the economy through increased investment efficiency is also confirmed (James, 2008).

\section{2-2-Relations between Foreign Trade and Economic Growth}

First, there are theories that the international trade literature relating to a trade school. The followers of this school would be positive balance of trade as the economic expansion. The other economists have different ideas about the relationship between foreign trade and economic growth proceeded.

Economy and Foreign Trade, different and sometimes conflicting theories exist. Existing theories about the impact of foreign trade on economic growth can be segregated into two categories. The first group includes advocates of free trade. This category of free trade as an engine of economic growth will teach, believe that free trade accelerates economic growth (Salvatoreh, 2009).

David Hume foreign trade as the engine of economic growth and political and economic development. Adam Smith (1999) on the benefits of free trade coherently argued in The Wealth of Nations and The Theory of absolute advantage $\neg$ has to offer. David Ricardo 's theory of comparative advantage, while providing the freedom to trade at a fixed target and became the UK 's economic policy. After Smith and Ricardo, Mill believed that international trade leads to greater efficiency of production factors at the international level $\neg$ and consider it as foreign direct advantage. He also believed that the expansion of international trade in goods and services markets is leading to improve the manufacturing process(Singer, 1990).

The second, incorporate the opponents of free trade. Those who argue that trade is an important factor in reducing growth and economic development in developing countries. This category may be named Friedrich List, who believes in the freedom of trade, think is ideal and is available only in the distant future. According to him, every country should ban imposed tariffs and goods to boost their production bases to pay.

\section{3 . Model}

\section{3-1. Data are presented}

This section defines and variables used in this study will be discussed. And the period of time is from 1980 to 2001 .

The variables used in this study are as follows :

LGDP: log of GDP in 1991 constant prices as an indicator of economic growth.

LTR: logarithm of the ratio of exports and imports of goods and services to GDP in constant prices in 1991 as compared to commercial

LINV: logarithm of domestic investment

LR: logarithm of interest rates on short term deposits for one year ( as an alternative to the interest rate )

LM: logarithm of the ratio of cash to GDP (M2/GDP) as indicators of financial depth

To estimate relationships between variables and Microfit4 Eviews5 software used. 


\section{3-2. Econometric methods}

Traditional econometric methods to empirical studies, based on the assumption of finitude is variable. But studies done in this area shows that many time series, it is incorrect to assume that most of these variables are unstable. This problem may cause spurious regression and destroy confidence in the estimated coefficients. Thus, the cointegration theory in modern econometrics is essential in estimation method using time series, using the co-integration of the coastal and take note.

The method of Engel - Granger, the resulting estimates, samples with small volume, due to the lack of consideration of short-term dynamic interactions between variables, bias is significant. Meanwhile, the limiting distribution of the least squares estimation of non markers are normal, so do statistical hypothesis testing using the routine is invalid. The method Engel - Granger co-integration vector is based on the existence of a default under conditions where there is more than one co-integration vector, using this approach will lead to inefficiency (Pesaran and Smith, 1998). To resolve these problems, Johansen (1989) and Johansen and Juselius Maximum Likelihood estimation method for mining cointegration tests suggest that co-integration vectors . (Johansen and Juselius, 1992) cointegration method Johansen and Juselius too, because all variables in the model may not have the same degree of reliability, it can be useful (Zaranezhad and Saadatmehr, 2007). In this article, since the degree of collective variables the case was different in its own way, thus explaining the distributional breaks (ARDL) has been used.

The ARDL method for each of the variables, using criteria such as the Schwarz - Bayesian, Akaike and Hanan Queen , interrupt optimally selects (Pahlavani and Dahmardeh, 2007), this method of long-term relationships and short-run relationship between the dependent variable and other explanatory variables of the model simultaneously estimates. Using this approach, the same degree of co-integration variables - the Engel method - Granger is essential - not needed. ARDL methodology in the case of variable combinations of variables are I (1) and I (0) , they are still applicable.

\section{3-3 . Explain your model breaks distributed (ARDL)}

General dynamic model, where the model breaks variables, as in equation ( 1 ) are entered.

$$
Y_{t}=a X_{t}+b X_{t-1}+c Y_{t-1}+u_{t}
$$

To reduce bias in the estimated coefficients of the model in small samples, it is possible to use a model that breaks a lot of variables, such as equation ( 1 ) to consider.

$$
\phi(L, P) Y_{t}=\sum_{i=1}^{k} b_{i}\left(L, q_{i}\right) X_{i t}+c^{\prime} w_{t}+u_{t}
$$

The relationship between the dependent variable and the independent variables are high . Lag operator $L$, and wt is the $S \times 1$ vector representing the predetermined variables in 
the model including the intercept, dummy variables, time trends and other variables are exogenous. $P$ interrupt number used to interrupt the dependent variable and $q$ the number of used for the independent variables.

This model explains a model with distributed interrupts (ARDL) is called, where we have:

$$
\begin{gathered}
\phi(L, P)=1-\phi_{1} L-\phi_{2} L^{2}-\ldots . \phi_{p} L^{p} \\
b_{i}\left(L, q_{i}\right)=b_{i 0}+b_{i 1} L+\ldots .+b_{i q} L^{q} \quad \mathrm{i}=1,2, \ldots, \mathrm{k}
\end{gathered}
$$

Interrupt number for each of the explanatory variables can be optimized with the help of Akaike criteria (AIC), Schwarz - Bayesian (SBC), Hanan - Quinn (HQC) and the adjusted coefficient of determination can be determined. Usually less than 100 samples, Schwartz scale - is Bayesian, so many degrees of freedom does not go away. The criteria for determining Interrupts savings and, as a result, will have to estimate the degree of freedom (Pesaran and Shin, 1996). To calculate the long-run coefficients of the model, the model is dynamic. Long-run coefficients of the variables $X$ are obtained from the relationship:

$$
\theta_{i}=\frac{\hat{b}_{i}\left(L, q_{i}\right)}{1-\hat{\phi}(L, p)}=\frac{\hat{b}_{i 0}+\hat{b}_{i 1}+\ldots+\hat{b}_{i q}}{1-\hat{\phi}_{1}-\hat{\phi}_{2}-\ldots-\hat{\phi}_{p}}, i=1,2, \ldots, k
$$

From equation ( 3-2), the t-statistic is calculated as the long-run coefficients are calculated . Inder (1993) show that the t statistics of this kind are common enough in the normal distribution and the t test based on the critical parameters normally be well. So to help generate valid test can be done on a long-term relationship. The ARDL method for estimating long-term relationship can be used to make a two-stage procedure . In the first phase of a long-term relationship between the variables under consideration are test (Pesaran et al, 2001). At this point, to examine the long-run relationship of this method is false, there are two ways :

In the first method estimates the dynamic model ARDL following hypothesis is tested :

$$
\begin{aligned}
& H_{0}: \sum_{i=1}^{p} \phi_{i}-1 \geq 0 \\
& H_{a}: \sum_{i=1}^{p} \phi_{i}-1 \prec 0
\end{aligned}
$$

Null hypothesis of no co-integration implies long-term relationships. To perform the test by Banerjee et al (Banerjee, et al, 1993), is presented, the number of coefficients in a fraction of the lag dependent variable and the sum of the coefficients divided by the standard deviation of the test statistic $\mathrm{t}$ - is obtained. 
( 7 )

$$
t=\frac{\sum_{i=1}^{p} \hat{\phi}_{i}-1}{\sum_{i=1}^{p} S_{\hat{\phi}_{i}}}
$$

If the absolute value of $t$-statistics obtained from the absolute value of the critical values provided by Banerjee and Master 's level is greater than $95 \%$ confidence, the null hypothesis was rejected based on the lack of co-integration and long-term relationship is accepted.

The second approach, which is presented by the boys and Shin , the long-run relationship between the variables under study by calculating the $F$ statistics for the test variables were significantly delayed in the form of error correction will be examined (Pesaran, and Shin, 1996).

In this section the reliability tests are conducted and the variables (2) I is the amount of computing F statistics cannot be trusted. Therefore, the results of this test in Table ( 1$)$ is provided

Table 1: Results of the unit root test with intercept and no time trend

\begin{tabular}{|l|c|c|c|}
\hline variable & The test statistic & Critical value & Conclusion \\
\hline LGDP & -1.6831 & -3.5529 & Unstable \\
\hline LINV & -4.3937 & -3.5484 & Stable \\
\hline LM & -3.2038 & -3.5529 & Unstable \\
\hline LR & -2.0878 & -3.5529 & Unstable \\
\hline LTR & -0.4221 & -3.5484 & Unstable \\
\hline
\end{tabular}

Source: Calculations researcher

Table 2: Results of static test variability in the intercept and time trend

\begin{tabular}{|l|c|c|c|}
\hline variable & The test statistic & Critical value & Conclusion \\
\hline LGDP & -1.8210 & -2.9540 & Unstable \\
\hline LINV & -4.3384 & -2.9511 & Stable \\
\hline LM & -1.1355 & -2.9604 & Unstable \\
\hline LR & -1.8338 & -2.9511 & Unstable \\
\hline LTR & 1.7241 & -2.9511 & Unstable \\
\hline
\end{tabular}

Source: Calculations researcher

As is clear from the results of unit root tests for all variables except investment levels are so unstable in the table (3) to assess the reliability of first-order difference variables will be discussed. 
The results are summarized in Table (3) concluded that all model variables except investment I (1) respectively. Since the variables of the study I (1) and I (0) are so selfexplanatory method with interrupts distributed (ARDL) is used to examine relationships between variables. At this point, we have evaluated the long-term relationship between the variables is discussed.

Table 3 : Results of unit root test on first-order difference variables with intercept and no time trend

\begin{tabular}{|l|c|c|c|}
\hline variable & The test statistic & Critical value & Conclusion \\
\hline$D(L G D P)$ & -3.5236 & -2.9540 & Stable \\
\hline$D(L M)$ & -3.5496 & -2.9604 & Stable \\
\hline$D(L R)$ & -4.9076 & -2.9540 & Stable \\
\hline$D(L T R)$ & -4.2096 & -2.9540 & Stable \\
\hline
\end{tabular}

Source: Calculations researcher

Using the model breaks, Dyagy ARDL $(1,0,0,0,0)$ selected as the optimal interval and the amount of computational statistics Banerjee, Dvladv and MasterCard and is determined by the following calculation:

$$
t=\frac{0 \cdot 06-1}{0 \cdot 14}=-6 \cdot 71
$$

Table base and Banerjee et al 95\% confidence level for the model with intercept -3.28 , so there is demonstrate long-term relationship between the variables.

Now with the knowledge to estimate the long-run relationship between the variables, resulting in an estimate Magu in Table 4 are presented:

Table 4: Estimation results of the long-term economic growth and financial development

\begin{tabular}{|l|c|c|c|c|}
\hline variable & LM & LINV & LTR & LRR \\
\hline Coefficients & 0.24 & 0.11 & 8.98 & -0.12 \\
\hline Standard deviation & 0.09 & 0.08 & 12.16 & 0.03 \\
\hline$T$ & 2.66 & 1.37 & 0.73 & -3.22 \\
\hline Critical value & 0.012 & 0.04 & 0.46 & 0.003 \\
\hline
\end{tabular}

According to the results of long-term co-integration vector $\neg$ can now conclude :

Variable is significant and positive effect of financial development on economic growth has increased in other words, an increase in financial development to economic growth in the long term .

Domestic investment is also positive and significant coefficient was obtained, and this suggests that economic growth increases with an increase in investment. But as the coefficient obtained is smaller than the other coefficients can be concluded vast amount of economic growth can not be explained by this factor .

is used, it is justified.

The coefficient of the real interest rate is negative and significant in relation to economic 
growth and this is an indication that the rise in interest rates, economic growth will be reduced by .

disruption of normal distribution and variance components are identical. So to estimate the error correction model are addressed, the results in Table ( 5 ) provides :

Table 5 : Estimation results of the short-term economic growth and financial development

\begin{tabular}{|l|c|c|c|c|}
\hline variable & dLINV & Dltr & dLR & Ecm(-1) \\
\hline Coefficients & 0.04 & 0.25 & -0.04 & -0.36 \\
\hline Standard deviation & 0.02 & 4.55 & 0.02 & 0.14 \\
\hline T & 1.48 & 0.05 & -2 & -2.43 \\
\hline
\end{tabular}

Source: Calculations researcher

The results of the short-term model represents a significant and positive impact of financial development on economic growth in Iran. The coefficient of domestic investment is also positive and significant impact on economic growth .

ECM coefficient is negative and significant value was obtained, and this model represents the dynamics of the short- term to long- term, short- term to long- term error correction process in terms of speed 0.36 is.

\section{4 . Conclusions and recommendations}

Different views on the relationship between economic growth and financial development there. First, financial development to economic growth - leading to a theory known as supply. Second, economic growth and demand for financial services raises the need for new financial instruments. Thus, economic growth, financial development is the formation factor. Third, the relationship between economic growth and financial development is important . Fourth, the relationship between economic growth and financial development and interactive simultaneously or in other words, the theory of supply and demand theory is the acknowledgment . Correct diagnosis of each of these relationships need to be studied in experimental economics. This paper examines the relationship between financial development and economic growth are self explanatory panels with breaks, (ARDL) was used. This study uses time-series data over the period 1352 to 1386 was performed.

Invest significant positive effect on economic growth in the long term and short term . Interest rates on short- term and long -term significant negative impact on economic growth .

The ratio of short- term and long -term business with a positive but statistically insignificant coefficient obtained.

\section{References:}

1- Asari, A. , Naseri, A.R. and Aghaee khoondabi, M.(2009)." Financial development and Economic Growth: Comparison of OPEC oil and non-oil developing countries, using the Generalized Method of Moment". Economic Research,.1-25 (In Persian).

2- Ben Naceur,M, and Ghazouani. B.(2007)." GMM estimation of empirical growth model". 
Working paper no. 2001-w21. University of oxford.

3- Banerjee, A., and et al.(1993)." Co-integration, error-correction, and the econometricanalysis of non-stationary data". Advanced Texts in Econometrics. Oxford, UK: Oxford University Press.

4- Goldsmith, R. W. (1969)." Financial structure and development". New Haven, CT7 Yale Univ. Press.

5- James, A.(2008)." What are the mechanisms linking financial development and economic growth in Malaysia?". Economic Modelling, 25 ,38-53.

6- Johansen, S., and Juselius. K. (1992)."Testing structural hypothesis in a multivariate cointegration analysis of the PPP andUIP for UK". Journal of Econometrics, 53. $211-244$.

7- Liang, Q. and Teng. J. Z.(2006)." Financial development and economic growth: Evidence from China", China Economic Review, 17,395-411.

8- Pahlavani, M. and Dahmardeh, N.(2007). "Import and export demand functions estimated in the Iranian economy using ARDLconvergence". Journal of Economic,3, 110-120 (In Persian).

9- Patrick, H.T. (1966)." Financial Sector Development and Economic Growth in Underdeveloped Economies", Economic Development and Cultural Change, 14, 174-189.

10- Pesaran, M. H. and Smith R.(1998)." Structural Analysis of Co-integration VARs". Journal of Economic Surveys, 12, 471-505.

11- Pesaran, M.H. and Pesaran. B.(1997)." Working with Microfit4.0: Interactive Econometric Analysis". Oxford: Oxford University Press.

12- Pesaran , M. H. and et al.(2001)." Bounds testing approaches to the analysis of level relationships".Journal of Applied Econometrics, 16, 289-326.

13- Pesaran , M.H., and Shin. Y.(1996)."Co-integration and speed of convergence to equilibrium". Journal of Econometrics, 71, 43-117.

14- Rasekhi, S. and Ranjbar, O.(2009)." The effect of financial development on economic growth in Organization of Islamic Conference countries". Journal of Knowledge and Development, 27, 1-22 (In Persian).

15- Rasti, M.(2009). "The relationship between financial development and economic growth in OPEC member countries: testing assumptions Patrick". Commercial Studies,38,59-67. (In Persian).

16- Ritab, S. A. (2007)."Financial Sector Development and Sustainable Economic Growth in Regionally Co-Integrated Emerging Markets". Advances in Financial Economics, 12,345-360.

17- Roozbehan, M.(2008)." The bases of Development Economics". $3^{\text {Th }}$ Ed,Tehran,Taban Publications (In Persian).

18- Salvatoreh, D.(2009)."International Trade". Translated by Hamid Reza Arbab,Tehran, Ney Publication (In Persian).

19- Singer, H.W. (1990). "U.S. Foreign Investment in Underdevelopment Areas". American Economic Review, Papers and Proceedings, No.40.

20- Suleiman, A. B. and Aamer. S. A.(2007)." Financial development and economic growth: The Egyptian experience". Journal of Policy Modeling, Article in Press.

21-Zaranezhad, M. and Saadatmehr, M.(2007)."Estimate the demand for meat in Iran". Journal of Humanities and Social Sciences (Particularly Economics), 26, 63-82. (In Persian). 